| Dossiê: Impactos e Repercussões Socioambientais de Empreendimentos na Pan-Amazônia| DOI: http://dx.doi.org/10.18764/2446-6549.e202011

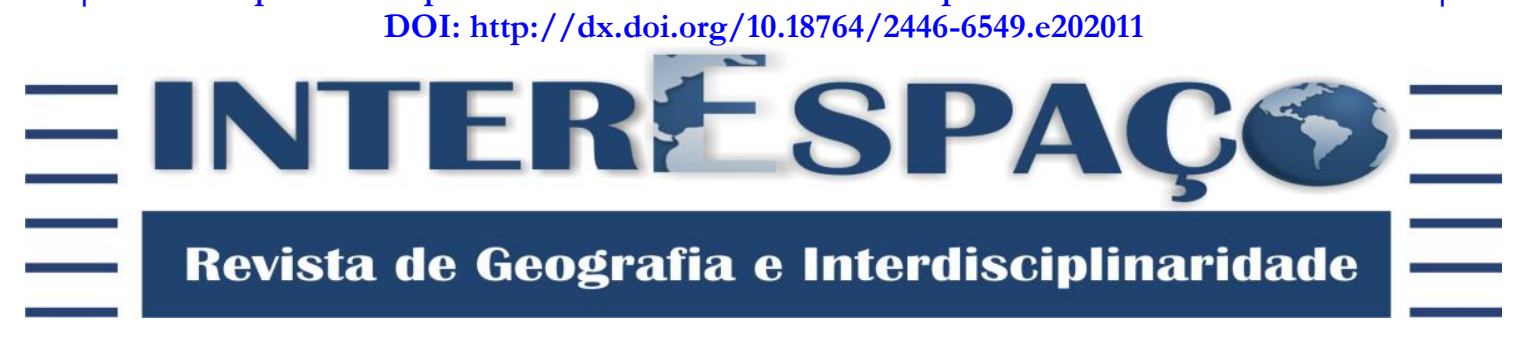

\title{
EFEITOS SOCIOAMBIENTAIS DA HIDRELÉTRICA DE TUCURUÍ EM AÇAIZAL, BAIÃO-PA: violação de direitos, conflitos e recomposição territorial
}

\author{
SOCIO-ENVIRONMENTAL EFFECTS OF THE TUCURUÍ \\ HYDROELECTRIC PLANT IN AÇAIZAL, BAIÃO-PA: violation of rights, \\ conflicts and territorial recomposition
}

\section{IMPACTS SOCIO-ENVIRONNEMENTAUX DU BARRAGE DE TUCURUÍ À AÇAIZAL, BAIÃO-PA: violation des droits, conflits et recomposition territoriale}

\section{Aquiles Simões}

Doutor em Estudos Rurais - Ciências Sociais pela Université de Toulouse II, França. Docente da Universidade Federal do Pará - PPGEDAM/NUMA/UFPA e PPGCITI/Campus de Abaetetuba/UFPA. Coordenador do GEDAF - Grupo de Estudos Diversidade Socioagroambiental na Amazônia. aqsimoes@pq.cnpq.br / http://orcid.org/0000-0003-2194-6594

\section{Matheus Benassuly}

Doutorando e Mestre em Antropologia pela Universidade Federal Fluminense - UFF. Pesquisador do GEDAF - Grupo de Estudos Diversidade Socioagroambiental na Amazônia. matheusbenassuly@id.uff.br / http://orcid.org/0000-0002-3751-3833

Recebido para avaliação em 30/06/2020; Aceito para publicação em 21/09/2020.

\section{RESUMO}

Objetiva-se demonstrar como os efeitos decorrentes da construção da Usina Hidrelétrica de Tucuruí incidem sobre o modo de vida ribeirinho, em uma comunidade de pescadores estabelecidos à jusante da barragem, no município de Baião-PA. Os pescadores exprimem, à sua maneira, a necessidade de reparação dos direitos que vêm sendo violados pela ação da Hidrelétrica. Com base no método compreensivo foram realizadas entrevistas semiestruturadas e reuniões para o diálogo crítico com os pescadores. Conclui-se que os efeitos socioambientais provocados pela construção da barragem incidem diretamente sobre os direitos humanos, instituem conflitos e ameaçam a manutenção dos modos de reprodução dos ribeirinhos, traduzindo-se em processos de desterritorialização e reterritorialização.

Palavras-chave: Baixo Tocantins; Pescadores; Flechação; Deslocamento.

\section{ABSTRACT}

The goal is to demonstrate how the effects of the construction of Tucuruí Hydro Plant focus on riversides livehood, in a community of fishermen established downstream of the dam, in Baião-PA. The fishermen express, by his own way, need to repair violated rights by the Plant activity. By the comprehensive method, we did semi-estructurated enterviews and some meetings to critic dialogue with the fishermen. The conclusion is wich the socio-environment effects from the dam building focus on the human rights, found conflicts and menace the maintenance of the riverside reproduction ways, traducing in the deterritorialization and reterritorialization processes.

Keywords: Baixo Tocantins; Fishermen; Flechação; Displacement. 
|Efeitos socioambientais da Hidrelétrica de Tucuruí em Açaizal, Baião-PA: violação de direitos, conflitos e recomposição territorial|

\section{|Aquiles Simões | Matheus Benassuly|}

\section{RÉSUMÉ}

L'objectif est de démontrer comment les effets résultant de la construction de l'hydroélectrique de Tucuruí affectent le mode de vie riverain, dans une communauté de pêcheurs établie en aval du barrage, dans la municipalité de Baião-PA. Les pêcheurs expriment, à leur manière, la nécessité de réparer les droits qui ont été violés par l'action de l'hydroélectrique. Soutenu par la démarche compréhensive, des entretiens semi-structurés et des réunions ont été organisés pour un dialogue critique avec les pêcheurs. Il est conclu que les effets socio-environnementaux causés par la construction du barrage affectent directement les droits de l'homme, instituent des conflits et menacent le maintien des modes de reproduction riverain, se traduisant par des processus de déterritorialisation et de reterritorialisation.

Mots-clés: Baixo Tocantins; Pêcheurs; Flechação; Déplacement.

\section{INTRODUÇÃO}

No atual contexto amazônico, observa-se a coexistência entre grandes projetos e povos e comunidades tradicionais, os quais têm uma relação particular com o meio ambiente, o que garante sua reprodução em um determinado território. Tal coexistência não é consensual, uma vez que não há grandes projetos que não incidam diretamente sobre os direitos humanos. Mesmo antes do início do processo de implantação de grandes projetos, a exemplo do Programa Grande Carajás (PGC), no qual se inscreve a Usina Hidrelétrica de Tucuruí (UHT), a Amazônia apresentava um cenário de disputas por modelos de desenvolvimento. Este projeto foi levado a cabo pelo governo federal em um contexto político conturbado, marcado pelo autoritarismo e por obscuridades (HALL, 1991). Isso acabou ensejando graves prejuízos às populações afetadas pela barragem de Tucuruí, bem como para toda a coletividade, no que diz respeito à consulta a essas populações e à confiabilidade da mensuração dos assim nomeados impactos ambientais, à época de sua instalação ${ }^{1}$.

A construção da UHT alterou o ambiente natural do rio Tocantins, dividindo-o em três territórios com ecossistemas distintos: montante, jusante e lago, com forte incidência sobre as comunidades ribeirinhas a jusante da barragem que vivem, em grande parte, da atividade pesqueira. Em geral, a preocupação de ambientalistas, governos e pesquisadores recaiu sobre as populações afetadas à montante da barragem e pela formação do lago, dada a necessidade de dar visibilidade a questão da destruição física e social, e, ao mesmo tempo, de quantificar os “impactos” resultantes desse tipo de intervenção. Magalhães (1996; 2007), ao analisar o processo de deslocamento compulsório de camponeses, em função da inundação causada pela UHT, de seu território para loteamentos rurais, ressalta a destruição

\footnotetext{
${ }^{1}$ Lucio Flávio Pinto (1982) registra os planos do Governo Federal para a região no sentido de "induzir o desenvolvimento" partindo de modelo historicamente oposto àquele consolidado na região. Tal modelo teria como princípio servir às indústrias do restante do país, atendendo suas demandas por energia.
} 
| Efeitos socioambientais da Hidrelétrica de Tucuruí em Açaizal, Baião-PA: violação de direitos, conflitos e recomposição territorial|

|Aquiles Simões | Matheus Benassuly|

das condições sociais de reprodução do grupo. A perda de tais condições, incluindo aí todo um universo cosmológico e uma forma de estar no mundo, relaciona-se diretamente a compulsória perda do território e, com ele, os seus recursos materiais e simbólicos.

Entretanto, o olhar aqui está voltado para as populações afetadas pelo projeto à jusante da barragem de Tucuruí, que possuem em comum com aqueles sujeitos um outro modo de classificar e de quantificar a vida, além de terem vivido processos de expropriação. Em relação a esse tipo de intervenção no espaço, a bibliografia sobre as condições sociais de existência de ribeirinhos (pescadores agricultores de várzea, enfim, poliprodutores (NEVES, 2009) reproduzidas a jusante de barragens é recente e relativamente escassa. Se, por um lado, determinados estudos buscam compreensão interdisciplinar do tema, ao colocar em diálogo dados econômicos, sociais e ambientais, no sentido de relacionar a percepção da redução de estoques pesqueiros ou da escassez do pescado à jusante de barragens, em sua dimensão quantitativa e qualitativa (LIMA; DORIA; FREITAS, 2012; SANTANA et al., 2014; FLEXA; SILVA; CINTRA, 2016; AVIZ et al., 2020); outros, na área das ciências sociais, notadamente na antropologia, centram-se em análises das lógicas de dominação expressas por conjuntos de valores morais internos aos documentos elaborados pelos planejadores, explicitando quadro epistemológico que opera na desconsideração dos chamados impactos à jusante das barragens (ACSELRAD, 2019; TEIXEIRA; ZHOURI; MOTTA, 2021). Trabalho recente em relativa aproximação da situação empírica que estamos a analisar por este texto (seu distanciamento reside, principalmente, pelo fato de que pelo território privilegiado a principal atividade laboral não corresponde à pesca), trata da perda do controle real sobre o território e do acesso aos recursos naturais em dois assentamentos rurais no município de Anapu-PA (GOMES; BRITO; PORRO, 2018). Ao analisar as limitações às práticas produtivas de agricultores familiares diante da legislação ambiental, os autores compreendem o processo expropriatório vivido (entendido como precarização das condições de vida naquele território) como des-territorialização in situ.

Entretanto, a discussão que propomos aqui difere das anteriormente enumeradas uma vez que incide especialmente sobre dados qualitativos construídos junto aos pescadores estabelecidos em uma comunidade específica, localizada à jusante da barragem de Tucuruí. Além da escala de análise e da construção qualitativa dos dados aqui proposta (em contraposição ao primeiro conjunto de autores citados e no mesmo sentido dos demais, mas por outra metodologia), como novidade, nossa abordagem se constitui também em denúncia, ao refletir criticamente e de maneira interdisciplinar sobre a questão da violação dos direitos humanos. Pretendemos elevar a denúncia a outras esferas, ao 
|Efeitos socioambientais da Hidrelétrica de Tucuruí em Açaizal, Baião-PA: violação de direitos, conflitos e recomposição territorial|

|Aquiles Simões | Matheus Benassuly|

encarar a realização da presente pesquisa como um encontro de diferentes racionalidades, a partir do qual sujeitos processualmente reconvertem saberes entre distintos campos e formas de conhecimento.

\section{CONDIÇÕES DE CONSTRUÇÃO DA PESQUISA}

O presente estudo foi realizado mediante levantamento de bibliografia a respeito do tema, bem como de construção de dados primários e secundários. Os dados primários, de natureza qualitativa, constituem-se de registros de entrevistas abertas junto aos interlocutores que fomos selecionando a partir do contato com a principal liderança da colônia de pescadores do município de Baião, estado do Pará. Ao adotar a perspectiva da observação direta e uso de entrevistas qualitativas semiestruturadas, assumimos que poderíamos deparar com um mosaico de situações, o que exigiu compreender as narrativas construídas de maneira relacional, ou seja, tomando o contexto de enunciação da fala como objeto de análise. Nos períodos de julho e agosto de 2013 e em novembro de 2014, realizamos 12 entrevistas, privilegiando a construção desses dados junto aos anciãos da comunidade, por nós selecionados de acordo com a faixa etária, atividade e gênero. Acreditamos que, assim, corresponderíamos à compreensão do processo expropriatório em sua dimensão diacrônica, pois muitas pessoas idosas ali residem desde o nascimento. Assim procedendo, foi-nos possível, ainda, perceber as distintas temporalidades (formas de perceber e marcar o tempo) e as interdependências entre os diferentes agentes.

Diante de observações preliminares a respeito da questão a ser valorizada por nós, e tendo em conta que não é possível estabelecer as relações de pesquisa aqui explicitadas, permanecendo imune às implicações da simples presença de agentes externos ao universo social das pessoas com as quais realizamos o presente trabalho, optamos por somar voz aos diferentes agentes mobilizados em favor da visibilidade dos efeitos socioambientais de barragens que atravessaram gerações - neste caso, efeitos relativamente desconsiderados pela "técnica" dos planejadores. A relacional operação de aproximação e distanciamento na interlocução construída junto aos agentes não é negligenciada, mas problematizada e apresentada como dado de pesquisa. Muitas vezes, apesar de destacado, não nos reconheciam somente como pesquisadores, mas como pessoas dotadas da capacidade de transpor suas denúncias para outras esferas e arenas (TURNER, 2008). Assim, com relação aos efeitos socioambientais vividos, pareceu-nos relevante considerá-los (ao contrário de como, por princípio, os planejadores de barragens os encaram). 
|Efeitos socioambientais da Hidrelétrica de Tucuruí em Açaizal, Baião-PA: violação de direitos, conflitos e recomposição territorial|

\section{|Aquiles Simões | Matheus Benassuly|}

A demonstração dos efeitos socioambientais em sua dimensão jurídica foi realizada por meio de levantamento e estudo de um corpus legislativo selecionado a respeito do tema (Constituição Federal de 1988 e Decreto 6.040/2007). Tomamos a literatura "doutrinária” produzida dentro da área do direito sobre a questão como fonte de discussão. Nesse intuito, procuramos estabelecer relação entre a situação empírica por nós observada e interpretada, a partir de um olhar etnográfico, e esse corpus legislativo e doutrinário. Foi necessário, assim, que adotássemos como mediador conceitual, entre dois universos interpretativos tão distintos, um modelo teórico elaborado no interior da própria área do direito. Em perspectiva interdisciplinar, a conceituação jurídica da posse agroecológica (BENATTI, 2004) é por nós reconvertida de um campo a outro e assumida como principal conector modelar e, portanto, instrumento comparativo, pela relação entre normativas impostas "de cima para baixo" e as normas criadas e recriadas pelos agentes em contexto de expropriação. Assim, foi possível construir a condição de violação de direitos como estruturante das relações conflituosas em situação de expropriação física e simbólica observada junto à comunidade.

A construção do trabalho de campo foi realizada junto à comunidade Açaizal, estabelecida à jusante da barragem de Tucuruí, às margens do rio Matacurá, um afluente do rio Tocantins (Figura 1). Estima-se, a partir de dados fornecidos pela Colônia de Pescadores Z-34, que cerca de 36 famílias habitem as quatro vilas integrantes da comunidade, a saber: Vila Medeiros (6 famílias), Vila Corrêa (4 famílias), Vila do Pução (6 famílias) e a Vila Nova do Açaizal (aproximadamente 20 famílias). As vilas Medeiros, Corrêa e Pução ficam inundadas no período da cheia, enquanto a Vila Nova do Açaizal se estabelece em terra firme, estando posicionada numa cota mais alta na paisagem local. 
|Efeitos socioambientais da Hidrelétrica de Tucuruí em Açaizal, Baião-PA: violação de direitos, conflitos e recomposição territorial|

|Aquiles Simões | Matheus Benassuly|

Figura 1 - Mapa de localização de Açaizal

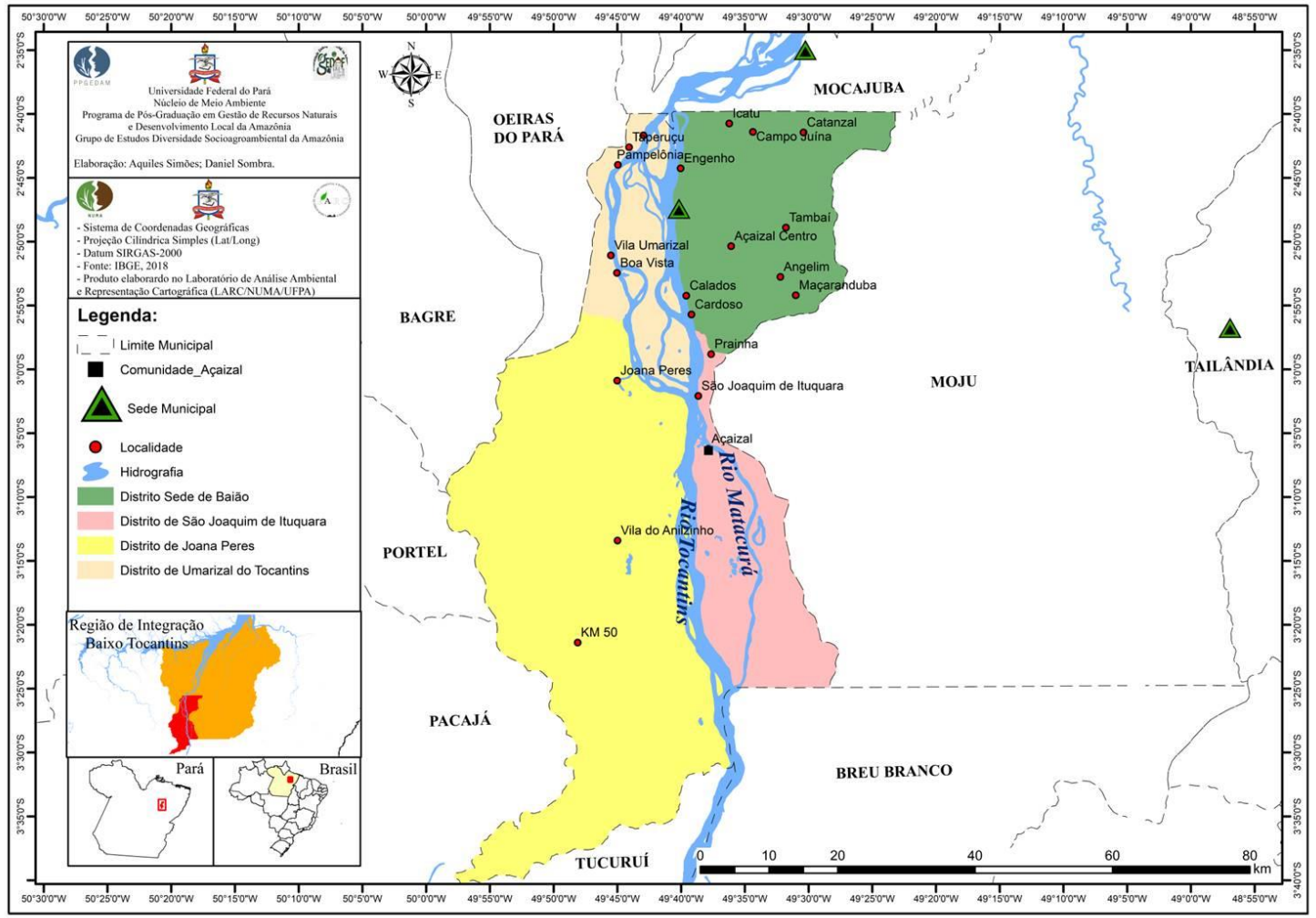

Fonte: Aquiles Simões e Daniel Sombra (2020).

A pesquisa é desenvolvida tendo em conta o interesse científico em torno dos graves efeitos socioambientais vividos naquela área a partir da construção da referida barragem (objetivada pela narrativa da escassez do pescado), bem como a dimensão política construída pela relação do grupo de pesquisa com diferentes agentes de intervenção no território do Baixo Tocantins (institucionalidades como associações e sindicatos de trabalhadores rurais e colônias de pescadores). Diante dessas premissas, a referência metodológica central para a interpretação das informações colhidas em campo é o método compreensivo (WEBER, 1994), fundamentado na interpretação dos acontecimentos passados e presentes. Assim, a partir das questões valorizadas pelos próprios sujeitos em interlocução no tempo presente da intervenção em trabalho de campo, operamos segundo a possibilidade de tematizar os eventos passados que perduram e atravessam diferentes gerações de pescadores. Entre os membros das oito famílias pescadoras as quais nos detivemos por este estudo, dois pescadores foram qualificados como informantes-chave, dada a sua condição de antigos moradores da comunidade e conhecedores da história social local, além do presidente da Colônia de Pescadores. As entrevistas e conversas informais em pequenas reuniões com grupos de pescadores foram registradas em caderno de campo, gravadas e posteriormente transcritas. 
|Efeitos socioambientais da Hidrelétrica de Tucuruí em Açaizal, Baião-PA: violação de direitos, conflitos e recomposição territorial|

\title{
|Aquiles Simões | Matheus Benassuly|
}

Para o desenvolvimento da pesquisa, partimos do pressuposto que as políticas e projetos de desenvolvimento se inscrevem numa perspectiva diacrônica. Nessa abordagem da socioantropologia do desenvolvimento, considera-se que:

\begin{abstract}
(...) estritamente falando, ninguém jamais viu uma política de desenvolvimento ou então a "ação pública". Uma política de desenvolvimento se define pelo que dizem as pessoas que a fazem: trata-se, portanto, de um conjunto de interações complexas entre lugares de reflexão ou de decisão macroeconômica, burocracias e administrações, grupos ou atores sociais (BARÉ, 2004, p. 106).
\end{abstract}

(...) Mais exatamente, estes sistemas de atores se inscrevem em uma temporalidade que lhes é constitutiva. Fala-se da "estrutura de uma história" tanto quanto da "história de uma estrutura", exatamente no sentido em que Sahlins empregava estas palavras no caso do Pacífico insular (BARÉ, 2004, p. 111).

(...) Mas trata-se essencialmente de pessoas, de atores que, a partir de um início hipotético, narram suas relações cambiantes: grosso modo, trata-se de um romance. (...) as políticas e projetos de desenvolvimento são romances ou capítulos de romance, com a diferença de que esses romances são tão realistas quanto possível e contam a história sempre renovada da ação pública. (...) Quando a antropologia reconstrói histórias a partir da memória coletiva, de uma memória coletiva essencialmente oral, dá-se a isso o nome de etno-história (BARÉ, 2004, p. 114-115).

Desse modo, o estudo procura demonstrar a circunscrição da população local numa lógica de produção agroecológica particular em oposição à lógica subjacente à noção de desenvolvimento. Ao compreender o modo como representam a experiência e refazem modos de vida diante da incômoda presença da UHT no seu cotidiano, foi-nos permitido refletir acerca dos desafios enfrentados pela comunidade e suas formas de resistir à dominação exercida pelas principais forças que operam na reelaboração do espaço. Tratamos, assim, de colocar em perspectiva a manutenção de reivindicados (e nem sempre reconhecidos) modos de vida, consectários de sua reprodução física, social e cultural naquele território, nas "margens do estado" (DAS \& POOLE, 2008). Evidencia-se, também, por meio da fala dos pescadores, os desafios à gestão do recurso natural de uso comum num cenário de violação de direitos e territorialidades emergentes.

A mortandade de peixes, segundo a fala dos pescadores, é uma das principais consequências da construção da barragem de Tucuruí, bem como a má qualidade da água. Nesse contexto, o uso de técnicas diferentes das tradicionais se destacam na prática da pesca de subsistência e de comercialização em pequena escala. Entretanto, essas técnicas, conforme dados construídos em campo, podem agravar a escassez do recurso. Nesse cenário, observa-se a emergência de conflitos e o acirramento da disputa por territórios entre os próprios indivíduos inseridos em tais comunidades. Assim, busca-se refletir sobre como a violação do direito fundamental ao meio ambiente ecologicamente equilibrado (art. 
|Efeitos socioambientais da Hidrelétrica de Tucuruí em Açaizal, Baião-PA: violação de direitos, conflitos e recomposição territorial|

|Aquiles Simões | Matheus Benassuly|

225 da Constituição Federal de 1988), ensejada pela ação da UHT, in casu, tem incidido sobre modo de vida ribeirinho, afetando a sua reprodução física, cultural e econômica, em radical oposição aos princípios e objetivos da Política Nacional de Desenvolvimento Sustentável dos Povos e Comunidades Tradicionais, Dec. 6.040/2007.

\section{VIOLAÇÃO DE DIREITOS, EFEITOS E CONFLITOS SOCIOAMBIENTAIS}

As informações colhidas em campo, por meio de entrevistas, revelaram a preocupação da comunidade com a perenidade do recurso natural. A diminuição do pescado foi observada, tanto em quantidade quanto na variedade de espécies, revelando inegável perda da diversidade da ictiofauna.

A denúncia se objetiva no discurso dos pescadores da comunidade, por meio de seu principal interlocutor, o presidente da Colônia de Pescadores Z-34: “A Eletronorte é a maior predadora, é a grande criminosa e responsável pela situação que vivemos, eles matam nossos peixes antes deles nascerem...”, mostrando indignação em sua fala, apoiada pelo grupo de pescadores durante a reunião coletiva com a comunidade. Constatamos, assim, que os pescadores operam em nível da consciência discursiva, ou seja, "tudo o que os atores conhecem (ou creem), de maneira tácita ou discursiva, sobre as circunstâncias de sua ação e daquela dos outros, e que eles utilizam na produção e reprodução de suas próprias ações" (GIDDENS, 1984). Assim, tornam evidente aos seus interlocutores os conflitos socioambientais existentes, construindo o discurso em forma de denúncia, claramente endereçado "para fora".

Os pescadores mais antigos da comunidade, que viveram o antes e o depois da construção da barragem, relataram que a construção da barragem ensejou, além de perda da agrobiodiversidade, transformações na paisagem. Há algumas espécies, de acordo com a experiência dos pescadores, que dependem do movimento das águas do rio, hoje controlado artificialmente pela barragem (Quadro 1). 
|Efeitos socioambientais da Hidrelétrica de Tucuruí em Açaizal, Baião-PA: violação de direitos, conflitos e recomposição territorial|

|Aquiles Simões | Matheus Benassuly|

Quadro 1 - Enumeração das perdas

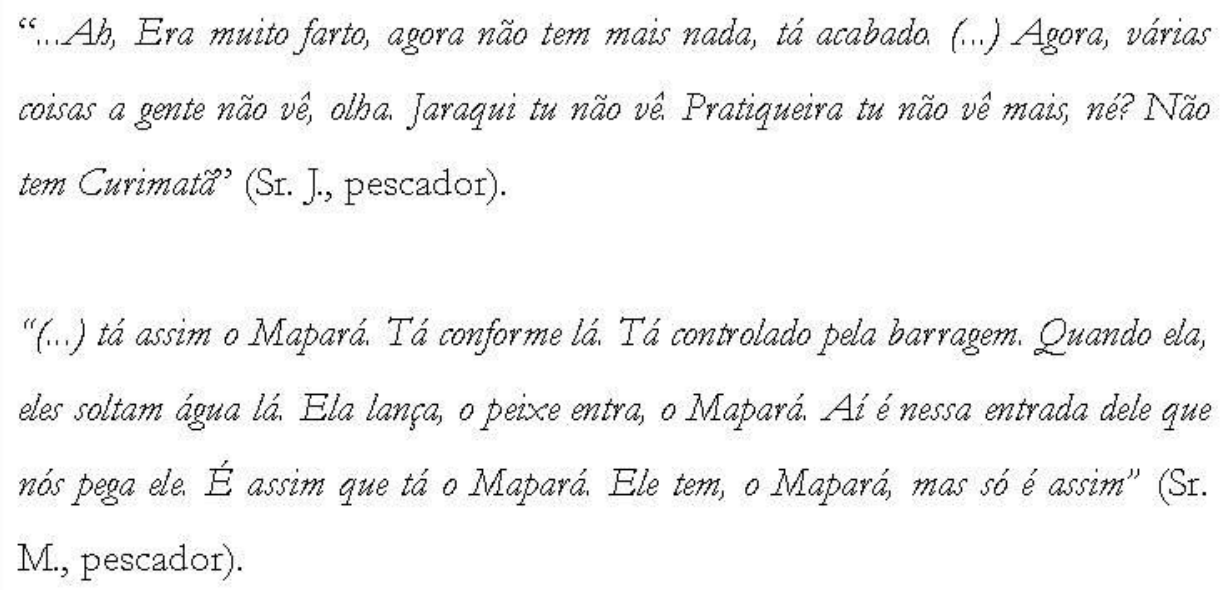

Fonte: Elaboração dos autores.

Quadro 2 - Transformações e perda da paisagem

"- ...Tem itha que sumitu, isso foi depois da barragem (...) foi tudo junto né, quando some, some tudo, as plantas, o aningal, as lagos onde os peixes entram para desovar (...) Aqui na vizinbança sumiu a ilba do Sacaí e do Xininga, elas não existem mais, tem lugar que o barco nem passa quando seca, vira um banco de areia só." (Sr. P., pescador).

Fonte: Elaboração dos autores.

Tais relatos (Quadro 2) exprimem bem as transformações ambientais vividas, decorrentes das mudanças na vazão do rio, desencadeando fenômenos como erosão e assoreamento dos rios.

Na Vila Nova do Açaizal, de ocupação recente, verificou-se a mudança nos hábitos dos pescadores. As famílias decidiram se estabelecer nessa área de terra firme, onde passaram a cultivar mandioca. Processualmente, o pescado perde a centralidade para a subsistência do grupo e aumenta a dependência de programas de transferência de renda, como o seguro defeso e o bolsa família. Observa-se, assim, uma recomposição dos modos de vida e a adoção de outras estratégias de reprodução social.

Evidencia-se, por tais transformações, a clara violação estatal ao direito ao meio ambiente ecologicamente equilibrado, consagrado pela Constituição em seu art. 225, este visto como direito humano fundamental, sendo, portanto, norma de aplicação direta pelo Poder Público, não se exigindo lei ordinária para sua regulamentação (BENJAMIN, 2007).

Em outro sentido, evidencia-se que os princípios e objetivos da Política Nacional de Desenvolvimento Sustentável dos Povos e Comunidades Tradicionais (PNPCT), 
| Efeitos socioambientais da Hidrelétrica de Tucuruí em Açaizal, Baião-PA: violação de direitos, conflitos e recomposição territorial|

|Aquiles Simões | Matheus Benassuly|

instituída pelo Decreto 6.040/2007, estão sendo desconsiderados pelo Poder Público (o que se depreende da confrontação da realidade aqui exposta com a leitura do art. $3^{\circ}$ do decreto em referência, mormente nos incisos I e IV), tendo em vista a omissão estatal junto às comunidades a jusante da barragem, especificamente à comunidade pescadora Açaizal. O Estado, reconhecido pelos sujeitos na forma da UHT, ao invés de aplicar as políticas ambientais constantes da Constituição e da legislação infraconstitucional, tem violado sistematicamente os direitos das comunidades pescadoras tradicionais à jusante da barragem.

\section{As "flechas do conflito" entre os pescadores}

A implantação da barragem, segundo as falas colhidas em campo, tem refletido na qualidade da água, no assoreamento do rio Matacurá (chamado pelos conhecedores da vida local como "boca da catinga", que é um afluente do rio Tocantins), na alteração da paisagem local, e ainda, de maneira destacada, na mortandade de peixes, evento ainda mais pronunciado no período de reprodução (piracema) e no período de "baixada da água", quando ocorre o piracaú.

O piracaú é um fenômeno ainda pouco mencionado pela bibliografia, foi observado também no Rio Tapajós, quando do estudo realizado no vale do Amazonas, em fins do século XIX, por uma comissão científica patrocinada pelo Governo Imperial, conforme vemos em Rodrigues (1875), que, ao descrever a paisagem local, assim classificou o acontecimento: "Esta cachoeira tinha outrora o nome de Piracaú aludindo ao peixe que se encontra às vezes morto ou de "bubuia" sobre as águas pelo embate das mesmas nas pedras". Explicou, ainda, o sentido etimológico, tendo como raiz o léxico indígena: "Pirá, peixe; caú, doudo". Em trabalho recente, em relação ao citado anteriormente, Hallwass (2011) afirma que o termo é utilizado regionalmente no território do Baixo Rio Tocantins, definindo brevemente o fenômeno em seu significado como "a mortandade sazonal de peixe".

No entanto, segundo os pescadores, o agravamento da escassez do pescado não é exclusivamente um efeito da barragem, ele resulta também das técnicas de pesca localmente utilizadas, sobretudo a utilização do açacu e a prática da flechação.

A flechação é compreendida como uma técnica trazida pelos "pescadores de fora" e adaptada pela geração mais jovem de pescadores da comunidade Açaizal. 
| Efeitos socioambientais da Hidrelétrica de Tucuruí em Açaizal, Baião-PA: violação de direitos, conflitos e recomposição territorial|

|Aquiles Simões | Matheus Benassuly|

Quadro 3 - Características da flechação

\begin{abstract}
"A pesca de flechação chegon aqui na comunidade por volta do ano de 2009... quem trouse foram os pescadores de Tucuruí. que entrou primeiro em Ituquara e vieram adentrando o beiradão que veio acabando com o peixe... agora está indo pros lagos da ressaca., eles seguem o caminho do mapará". J.C.F, 29 anos, pescador, Vila Corrêa)

"(...) essa flechação são os mais novos, essa molecadas que fažem, eles não escutam os mais velhos e vão pegando tudo o que eles estão vendo na frente deles. eles não estão nem á́... nãa tem medo de um dia isso acabar.e a gente é que tem que passar fome por causa disso". (J.F.L, 34 anos, pescador, Vila Poção).
\end{abstract}

Fonte: Elaboração dos autores.

Segundo os pescadores (Quadro 3), a flechação consiste na captura de peixe de diversas espécies e tamanhos, através do acesso aos chamados "berçários" durante o período noturno. Os flechadores utilizam máscaras de mergulho e pistolas de fabricação artesanal, além de malhadeiras e a lanterna para auxiliar na visualização do peixe à noite. Assim, o "berçário" é escolhido e bloqueado com uso de malhadeiras, após isso, os flechadores mergulham no local, direcionando o foco de luz emitido pela lanterna em direção ao peixe escolhido, o que facilita a sua captura e dispersa outros peixes, que ficam presos nas malhadeiras. Essa técnica, também conhecida como "flechação no fundo", tem provocado problemas na comunidade, sendo o maior deles a escassez de alimento para a maioria das famílias, e, por isso, é tida como proibida pelos habitantes da comunidade de Açaizal.

Com a finalidade de conter a prática, pescadores e usuários do recurso têm denunciado aos órgãos tidos como punitivos. Mas as denúncias não surtem efeito, uma vez que esses órgãos não têm adotado as medidas necessárias, levando a população que é contra a flechação a tomar iniciativas que eventualmente provocam confronto físico e ameaças de morte por parte daqueles que defendem a flechação como meio de sobreviver, diante da insegurança alimentar (Quadro 4). Tal conflito assenta-se, assim, na desigualdade de distribuição e acesso a tais bens de uso comum. 
|Efeitos socioambientais da Hidrelétrica de Tucuruí em Açaizal, Baião-PA: violação de direitos, conflitos e recomposição territorial|

|Aquiles Simões | Matheus Benassuly|

Quadro 4 - Representação do conflito com flechadores

"(...)Eles [os flechadores] ainda me ameaçam, falam que vão me meter no fundo, me alagar de noite aquin. tem noite que eu não durmo, as verges quando eu me espanto eles já estão ai dentro ilumiando no fundo.. eles não gostam de mim...tem raiva de mim por que en enfrento mesmo eles, boto um facão dentro do casco e vou atrás deles". (R.R.A, 45 anos, pescadora, Vila Pocina).

Fonte: Elaboração dos autores.

Relatos como esses também chamam a atenção, em nossos interlocutores, para a oposição cosmológica no conflito geracional observado nessa situação empírica. Os mais antigos pescadores do lugar remetem à adoção de técnicas artesanais de pesca, apreendidas e transmitidas pela tradição local, com o uso de ferramentas como caniço, lança, arco e flecha, ou com a abertura de largas cavidades nas margens do rio. Construídas principalmente pelos pescadores acima dos 70 anos, isto é, por pessoas que vivenciaram o período anterior à intervenção da UHT na região (qualificado como um período de fartura por esses interlocutores), as narrativas sugerem apropriações de saberes tradicionais em acordo com determinada ancestralidade afroindígena amazônica. Entre os relatos registrados em campo, alguns deles remetiam à força e à expressividade das narrativas míticas. Uma delas, a demonstrar, qual dramatizada "metáfora radical" (TURNER, 2008), a fartura daquele rio e a fragilidade de supostas fronteiras entre natureza e cultura (WAGNER, 2010), contava-nos sobre avós indígenas que, ao apontar o arco e flecha para cima, sempre conseguiam acertar em um peixe.

Observamos que pescadores dentro da faixa etária de 30 a 50 anos, apropriaram-se majoritariamente da pesca com malhadeira. Entre os mais jovens, como já dito, prevalece a técnica da flechação e açacu.

Acreditamos, assim, que as práticas tidas como predatórias seriam consequência da crescente dificuldade em se conseguir o pescado a partir dos efeitos da barragem. Postulamos que o agravamento da escassez é proporcional à agressividade das técnicas utilizadas pelos pescadores, que se desdobra em efeitos na perenidade do recurso. A evidência encontra-se na própria fala dos pescadores mais antigos. "tá difícil o peixe. Aí pra pegar eles tem que jogar o veneno" (Sr. J., pescador).

\section{Deslocamento in situ e recomposição territorial}

Observamos que os problemas na gestão refletem na dinâmica do grupo no que diz respeito às características atinentes à concepção jurídica da posse agroecológica 
| Efeitos socioambientais da Hidrelétrica de Tucuruí em Açaizal, Baião-PA: violação de direitos, conflitos e recomposição territorial|

|Aquiles Simões | Matheus Benassuly|

(BENATTI, 2004). Um dos elementos importantes para a caracterização da posse agroecológica é a área de uso comum, que, no caso em tela, é, principalmente, as águas (rio Matacurá). Esse elemento é que garante a coesão do grupo, fazendo com que adote normas historicamente construídas para a gestão do recurso de modo a que não se esgote, caracterizando o uso sustentável daquele território, o que é necessário para a conformação de tal concepção dentro da perspectiva agroecológica. Inferimos, a partir dos relatos, que as formas de organização estavam pautadas nas apropriações dos bens e serviços do meio ambiente a partir do extrativismo de base agroecológica.

Notamos que a organização da comunidade está em transformação, tendo em vista que o grupo não consegue levar adiante as negociações internas para a construção de dispositivos que visem manter o recurso para o uso da comunidade. As assimetrias entre os interesses dos pescadores têm levado à recomposição das estratégias de reprodução, como por exemplo, o deslocamento de pessoas das ilhas e várzeas em direção às áreas de terra firme e o investimento em novas atividades produtivas, abdicando da pesca ou tornando-a atividade secundária, como é o caso das famílias que se estabeleceram em Nova Açaizal.

Observamos que a comunidade também passou por deslocamentos físicos dentro de um mesmo espaço. Segundo os relatos e anotações em caderno de campo, por conta de fatores como a cheia do rio, famílias inteiras deslocaram-se para fundar a Vila Nova Açaizal, desvelando, assim, uma tentativa de manter a reprodução social do grupo por aquele território, em que se realiza sua identidade. A pesca, apesar disso, vem gradualmente perdendo a importância econômica para essas famílias, já que o aumento da penosidade, do esforço físico e do tempo de trabalho, e baixa rentabilidade, impedem ou limitam sua prática diária.

Advogamos que uma alternativa para esse grupo seja a busca por modelos de autogestão pautados na cooperação, na reciprocidade, nas relações de confiança, valores estes traduzidos em dispositivos normativos visando à obtenção de melhores resultados no manejo do recurso, a exemplo dos acordos de pesca que já vêm sendo praticados em outras comunidades situadas à jusante e igualmente afetadas pela barragem (SIMÕES; DIAS, 2013).

Muito embora não exista um modelo único e fechado que seja aplicável a todas as situações, cada grupo deve ter autonomia para criar suas próprias normas acerca do recurso que explora, há amplo acúmulo de conhecimento acerca do recurso em questão. A base empírica, a experiência social, deve ser posta em destaque para que os objetivos em torno dos recursos sejam alcançados (OSTROM, 2000, p. 43). 
|Efeitos socioambientais da Hidrelétrica de Tucuruí em Açaizal, Baião-PA: violação de direitos, conflitos e recomposição territorial|

\section{|Aquiles Simões | Matheus Benassuly|}

Entretanto, uma das questões que emergem da reflexão em torno de processos compulsórios de perda ou restrição do acesso aos bens e serviços comuns, como é o caso da restrição observada em Nova Açaizal, diz respeito aos limites da elaboração de um acordo de pesca por esses pescadores. Haveria possibilidade de um acordo de pesca diante de tantas restrições impostas de antemão (pela ação da barragem) aos pescadores daquela comunidade?

Por ora, podemos apenas lançar luz a tal questão a partir do reconhecimento da compulsoriedade não somente da perda do acesso, mas, sobretudo, neste caso, da perda do controle sobre suas condições de existência e de reprodução social. Apesar de o deslocamento físico não estar tão destacado pela situação empírica em questão, acompanhamos o entendimento de Zhouri, Oliveira e Motta (2013), no sentido de questionar a própria noção de espaço, uma vez que perdas, restrições e esvaziamento de direitos, status, constituem, também, formas de deslocamento. Para os autores, a compulsoriedade das alterações nas condições de existência, com modificações nas posições sociais, especialmente nas condições de vulnerabilidade e risco, é o que caracteriza deslocamentos desse tipo, que podem ser classificados como deslocamentos in situ.

O deslocamento in situ se refere, assim, a processos em que as pessoas permanecem no lugar, mas têm suas condições de existência significativamente alteradas, modificando sua posição social, em especial suas condições de vulnerabilidade e risco. Nessa medida, o deslocamento compulsório diz respeito não ao movimento físico em si, mas às relações de inclusão e exclusão a partir das quais as pessoas perdem acesso e controle sobre suas condições de existência e reprodução social, incluindo, recursos naturais e materiais, moradia, segurança, redes de solidariedade, confiança e parentesco (ZHOURI; OLIVEIRA; MOTTA, 2013, p. 3).

O redimensionamento do conceito de deslocamento compulsório (MAGALHÃES, 2007), a partir do questionamento da noção de espaço, abre novos leques de questões a partir da especificidade de situações empíricas em que diferentes agentes buscam lidar com as perdas e restrições vividas. O deslocamento vivido em Açaizal também produziu diversidade de interesses e estratégias, constituindo-se como elemento que desafia a compreensão usual sobre os efeitos socioambientais de barragens e sua duração no tempo.

Nova Açaizal guarda características da compulsoriedade dos processos vividos com a instalação da barragem de Tucuruí, a jusante. O território, entendido aqui como resultado de um esforço coletivo do grupo (territorialização) "para ocupar, usar, controlar e se identificar com uma parcela específica de seu ambiente biofísico" (LITTLE, 2002, p. 3), tem sido objeto de adaptações e rearranjos diante de forças opostas a sua constituição. A recomposição desse esforço coletivo (a reterritorialização) é desafiada pela desarticulação 
| Efeitos socioambientais da Hidrelétrica de Tucuruí em Açaizal, Baião-PA: violação de direitos, conflitos e recomposição territorial|

|Aquiles Simões | Matheus Benassuly|

de interesses dos diferentes agentes, o que podemos observar pelas diferentes narrativas em torno do uso dos recursos naturais. Produzidos a partir da ação/intervenção da barragem (principal agente operante na desterritorialização do grupo), tais interesses expressam demandas cada vez mais específicas, individuais e múltiplas.

A situação empírica em foco exige lidar com as diferentes cosmologias no conflito intergeracional, as múltiplas territorialidades, a escassez do recurso/insegurança alimentar e as pressões ambientais, assim como considerar tais conflitos como efeitos da UHT. Como construir um acordo de pesca em face dessa complexidade?

\section{CONCLUSÃO}

A construção da barragem, transformando um ecossistema lótico em lêntico, provocou sérios desequilíbrios no rio Tocantins, impactando, sobretudo a sua jusante, pois a vazão do rio passou a ser controlada pela Eletronorte. Isso repercute de forma intensa sobre a vida dos ribeirinhos, desdobrando-se em conflitos, violações de direitos humanos e pressões sobre a atividade pesqueira. Assim sendo, o fortalecimento sócio-político nos parece condição necessária para a manutenção dos modos de reprodução desses ribeirinhos, bem como para a perenidade do pescado, recurso comum que é a base de coesão da comunidade.

A pesca de flechação, utilizada pelas gerações mais jovens de pescadores de Açaizal, conforme empiricamente destacado, tem operado na amplificação da escassez de pescado provocada pela construção da barragem de Tucuruí, instaurando conflitos entre os pescadores e incidindo na segurança alimentar. Apesar das denúncias, a prática continua sendo levada adiante, o que dificulta, inclusive, a formação de um consenso em torno da possibilidade da instituição de acordo de pesca no local. A técnica, a despeito de ser considerada predatória, segundo depreende-se das falas dos pescadores, constitui uma estratégia à manutenção da reprodutibilidade física e social dessas pessoas.

Os deslocamentos in situ (perda do controle das condições de existência e reprodução social sem haver necessariamente deslocamento físico, como realocação) também supõem processos de desterritorialização e reterritorialização dessa população (LITTLE, 2002). A comunidade estudada revela um cenário no qual se conflitam políticas públicas, lógicas agroextrativistas e modos de vida tradicionais. A luta dos pescadores e das pessoas que ali vivem para permanecer no território se configura como um processo de resistência, revelado pela criação de estratégias para lidar com a escassez, tendo em vista a 
|Efeitos socioambientais da Hidrelétrica de Tucuruí em Açaizal, Baião-PA: violação de direitos, conflitos e recomposição territorial|

|Aquiles Simões | Matheus Benassuly|

manutenção da reprodução social naquele lugar. Trata-se, com efeito, de territorialidades emergentes num espaço marcado por profundas transformações socioambientais.

\section{REFERÊNCIAS}

ACSELRAD, H. A "memória técnica" das grandes barragens. Considerações sobre a aplicação da noção de memória a fatos técnicos. Novos estud. CEBRAP, São Paulo, v. 38, n. 02, p. 389-408, maio/ago. 2019.

AVIZ, J. S. [et al.]. A pesca artesanal do camarão-da-amazônia em municípios a jusante da Usina Hidrelétrica de Tucuruí: características tecnológicas, socioeconômicas e ambientais.

Research, Society and Development, v. 9, n. 7, e62973747, 2020.

BARÉ, J. A antropologia e as políticas de desenvolvimento: algumas orientações. Antropolítica, Nitéroi, v. 2, n. 17, p. 99-121, jul./dez. 2004.

BENATTI, J. H. Posse agroecológica \& manejo florestal. Curitiba: Juruá, 2004.

BENJAMIN, A. H. Constitucionalização do ambiente e ecologização da Constituição brasileira. In: CANOTILHO, José Joaquim Gomes; LEITE, José Rubens Morato (Org.). Direito constitucional ambiental brasileiro. São Paulo: Saraiva, 2007. p. 57-130.

DAS, V.; POOLE, D. El estado y sus márgenes. Etnografías comparadas. Cuadernos de Antropología Social, n. 27, p. 19-52, jul. 2008.

FLEXA, C. E.; SILVA, K. C. A.; CINTRA, I. H. A. Pescadores artesanais a jusante da Usina Hidrelétrica de Tucuruí, Amazônia, Brasil. Bol. Inst. Pesca, São Paulo, v. 42, n. 1, p. 221-235, 2016.

GIDDENS, A. La constitution de la société. Paris: PUF, 1984.

GOMES, D.; BRITO, A.; PORRO, N. Ambientalismo e des-territorialização in situ em assentamentos na Amazônia. Estudos Sociedade e Agricultura, v. 26, n. 1, 2018.

HALL, A. L. Amazônia: desenvolvimento para quem? Desmatamento e conflito social no Programa Grande Carajás. Rio de Janeiro: Jorge Zahar, 1991.

HALLWASS, G. Ecologia humana da pesca e mudanças ambientais no Baixo Rio Tocantins, Amazônia Brasileira. 2011. 91 f. Dissertação (Mestrado em Ecologia) Programa de Pós-Graduação em Ecologia, Universidade Federal do Rio Grande do Sul, Porto Alegre, 2011.

LIMA, M. A. L.; DORIA, C. R. C.; FREITAS, C. E. C. Pescarias artesanais em comunidades ribeirinhas na Amazônia brasileira: perfil socioeconômico, conflitos e cenário da atividade. Ambiente \& Sociedade, São Paulo, v. 15, n. 2, p. 73-90, ago. 2012.


out. 2020.

LITTLE, P. E. Territórios sociais e povos tradicionais no Brasil: por uma antropologia da territorialidade. Brasília: ISA - Instituto Socioambiental, 2002. (Série Antropologia, 322). 
|Efeitos socioambientais da Hidrelétrica de Tucuruí em Açaizal, Baião-PA: violação de direitos, conflitos e recomposição territorial|

|Aquiles Simões | Matheus Benassuly|

MAGALHÃES, S. B. Lamento e dor. Uma análise socioantropológica do deslocamento compulsório provocado pela construção de barragens. 2007. 278 f. Tese (Programa de PósGraduação em Ciências Sociais em co-tutela com a École Doctorale Vivant et Sócietés) Universidade Federal do Pará e Universidade Paris 13, 2007.

MAGALHÃES, S. B. O desencantamento da beira. Reflexões sobre a transferência compulsória provocada pela Usina Hidrelétrica de Tucuruí. In: ; CASTRO, E.; BRITTO, R. (Org.). Energia na Amazônia: avaliação e perspectivas sócio-ambientais. Belém: MPEG/UFPA/UNAMAZ, 1996. p. 697-746. v. 2.

NEVES, D. P. Os ribeirinhos-agricultores de várzea: formas de enquadramento institucional. Novos Cadernos NAEA, v. 12, n. 1, p. 67-92, jun. 2009.

OSTROM, E. El gobierno de los bienes comunes. La evolución de las instituiciones de acción colectiva. Cidade do México: UNAM-CRIM-FCE, 2000.

PINTO, L. F. Carajás, o ataque ao coração da Amazônia. Rio de Janeiro: M. Zero; Studio Alfa, 1982.

RODRIGUES, J. B. Exploração e estudo do vale do Amazonas: Rio Tapajós. Rio de Janeiro: Typographia Nacional, 1875.

SANTANA, A. C. [et al.]. Influência da barragem de Tucuruí no desempenho da pesca artesanal, estado do Pará. Rev. Econ. Sociol. Rural, Brasília, v. 52, n. 2, p. 249-266, jun. 2014. Disponível em: < https://doi.org/10.1590/S0103-20032014000200003 >. Acesso em: 05 out. 2020.

SIMÕES, A.; DIAS, S. C. O papel das organizações camponesas na construção do território da ação pública. In: CONGRESSO DA ASSOCIAÇÃO LATINO AMERICANA DE SOCIOLOGIA - ALAS, 29., 2013, Santiago. Anais... Crisis y Emergencias Sociales en America Latina. Santiago: FACSO/SocioRED/ALAS, 2013.

TEIXEIRA, R. O. S.; ZHOURI, A.; MOT'TA, L. D. Os estudos de impacto ambiental e a economia de visibilidades do desenvolvimento. Rev. Bras. Ci. Soc., São Paulo, v. 36, n. 105, e3610501, 2021. Disponível em: < https://doi.org/10.1590/3610501/2020>. Acesso em: 05 out. 2020.

TURNER, V. Dramas, Campos e Metáforas. Niterói: EdUFF, 2008.

WAGNER, R. A invenção da cultura. São Paulo: Cosac Naify, 2010.

WEBER, M. Economia e sociedade: fundamentos da sociologia compreensiva. 3. ed. Brasília: UnB, 1994. v. 1.

ZHOURI, A., OLIVEIRA, R. MOTTA, L. Deslocamentos Múltiplos e a compulsoriedade do desenvolvimento: urbanização e barragens em face aos lugares. In: XXXI INTERNATIONAL CONGRESS OF THE LATIN AMERICAN ASSOCIATION (LASA), Washington D.C., 29 May- 1st June, 2013.

Como citar este artigo: 
|Efeitos socioambientais da Hidrelétrica de Tucuruí em Açaizal, Baião-PA: violação de direitos, conflitos e recomposição territorial|

|Aquiles Simões | Matheus Benassuly |

\section{ABNT}

SIMÕES, A.; BENASSULY, M. Efeitos socioambientais da Hidrelétrica de Tucuruí em Açaizal, Baião-PA: violação de direitos, conflitos e recomposição territorial. InterEspaço: Revista de Geografia e Interdisciplinaridade, v. 6, e202011, 2020. Disponível em: <http://dx.doi.org/10.18764/2446-6549.e202011>. Acesso em: 25 jan. 2020.

\section{APA:}

Simões, A., \& Benassuly, M. (2020). Efeitos socioambientais da Hidrelétrica de Tucuruí em Açaizal, Baião-PA: violação de direitos, conflitos e recomposição territorial. InterEspaço: Revista de Geografia e Interdisciplinaridade, v. 6, e202011. Recuperado em 25 janeiro, 2020, de http://dx.doi.org/10.18764/2446-6549.e202011

\section{@creative}

This is an open access article under the CC BY Creative Commons 4.0 license.

Copyright (C) 2020, Universidade Federal do Maranhão.

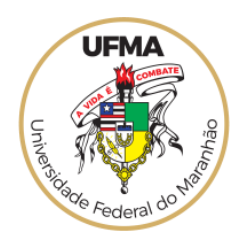

